\title{
THE ARTIFICIAL COOLING OF SICK-ROOMS IN SUMMER
}

\author{
A PRELIMINARY REPORT * \\ HENRY HEIMAN, M.D. \\ NEW YORK
}

The mortality of gastro-enteritis in infants, despite all scientific efforts devoted to its amelioration, is so appalling, that each summer, in addition to employing what is best in the old methods of treatment, we attempt to devise newer and better ways of combating this formidable disease. It was with this in view that during my summer service of 1913, an endeavor was made to attack this malady in a way entirely different from any previously undertaken.

The etiology of gastro-enteritis has been and will be for years to come a much discussed subject. Without reiterating the well known conclusions of many pediatrists, based on theoretical considerations and practical observations, let us state that in our opinion also, gastroenteritis is probably primarily a nutritional disorder, having as a secondary causal factor a bacteriologic basis. Both of these factors operate in winter as well as in summer. To account, then, for the marked prevalence of diarrheal diseases in summer we must consider a third potent cause, namely, the heat.

In order to determine the exact part heat really plays in the production of these summer diarrheas, and the effect of treatment in a routine manner with this important factor eliminated, a cooling plant was installed at the suggestion of Dr. Goldwater, superintendent of the hospital, in one small ward of the children's pavilion whereby the temperature of the room was kept constantly lower than that of the outside atmosphere. In brief, the method of cooling was as follows :

Outdoor air is forced by a motor-driven Sirocco fan through a waterchamber in which the water is cooled by brine coils. From this chamber the air is forced through an upper chamber filled with additional brine coils, thence through short ducts into the wards, where the cooled air enters near the floor level. Open transoms allow the warmer strata of vitiated air to

* Submitted for publication, May 27, 1914.

* From the Children's Service of Dr. Henry Koplik, Mt. Sinai Hospital, New York.

* Read at the meeting of the American Pediatric Society, Stockbridge, Mass., May 27, 1914. 
escape from the top of the rooms. Some air also escapes through the entrance door when used by the nurse and the physician. The cooling plant proper is located in the basement under room No. 1, as shown on plan, Figure 1. It consists of a Greef air washer, a motor-driven blower and coils through which cold brine is forced, an eliminator for removing the free particles of moisture and heating coils for reheating the air, if so desired. ${ }^{1}$

The temperature was recorded by means of two recording thermometers, one registering the outdoor temperature, the other that of the room. The relative humidity was ascertained by a sling psychrometer. Observations of the temperature and relative humidity were also taken in the general ward where no cooling was done.

Typical charts of the recording thermometers are reproduced in Figure 2, showing the records for the hours from 9 a. m., July 31,
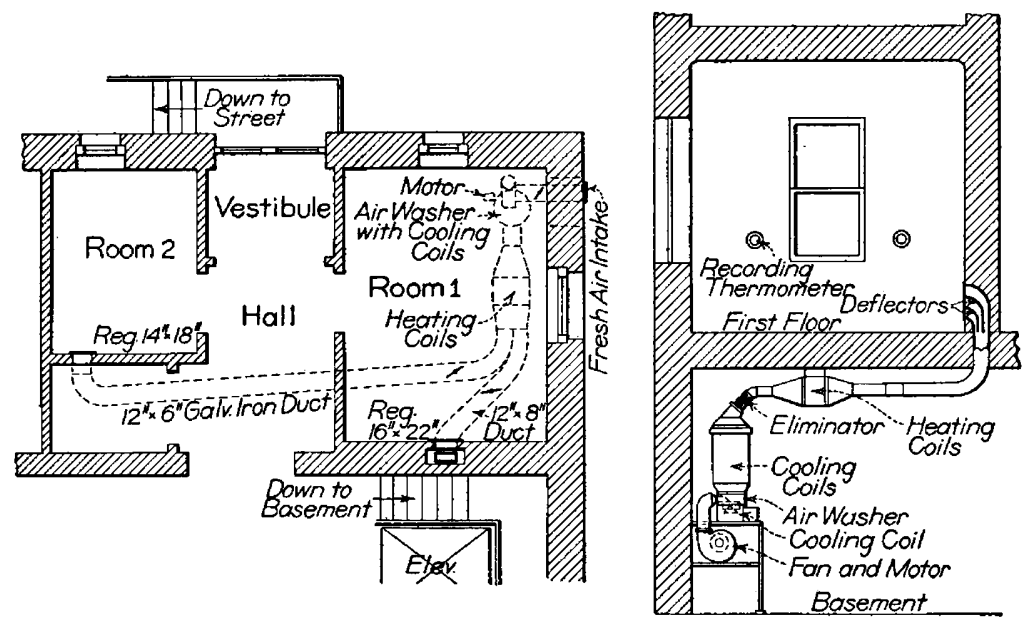

Fig. 1.-Location and details of air-cooling plant.

1913. The outdoor temperature, as will be noticed, was $86 \mathrm{~F}$. at 9 a.m., rising gradually to an average of 92 between $1: 30$ and 4: p. m., then dropping gradually to 78 between $5 \mathrm{p} . \mathrm{m}$. and $6: 30 \mathrm{p}$. m., when it began to rise again. The indoor temperature of the room was maintained at an average of 72 between 9 a. m. and 3 p. m., rising gradually to 74 at 7 p. m., which latter temperature was maintained until midnight, then rising to 75 until 4 p. m., dropping again to 74 until 7 a. $\mathrm{m}$. and 72 at $8: 45$ a. $\mathrm{m}$. The temperature in the cooled room varied during the period of observation from 63 to 74 . This latter temperature was reached only on one day when the temperature on the street rose to 93 . The average temperature in the cold room for 252 readings was 69 during a period of forty-two days. The

1. From a description by A. M. Feldman, M. E., Consulting Engineer, in the Proceedings of the American Society of Heating and Ventilating Engineers. 


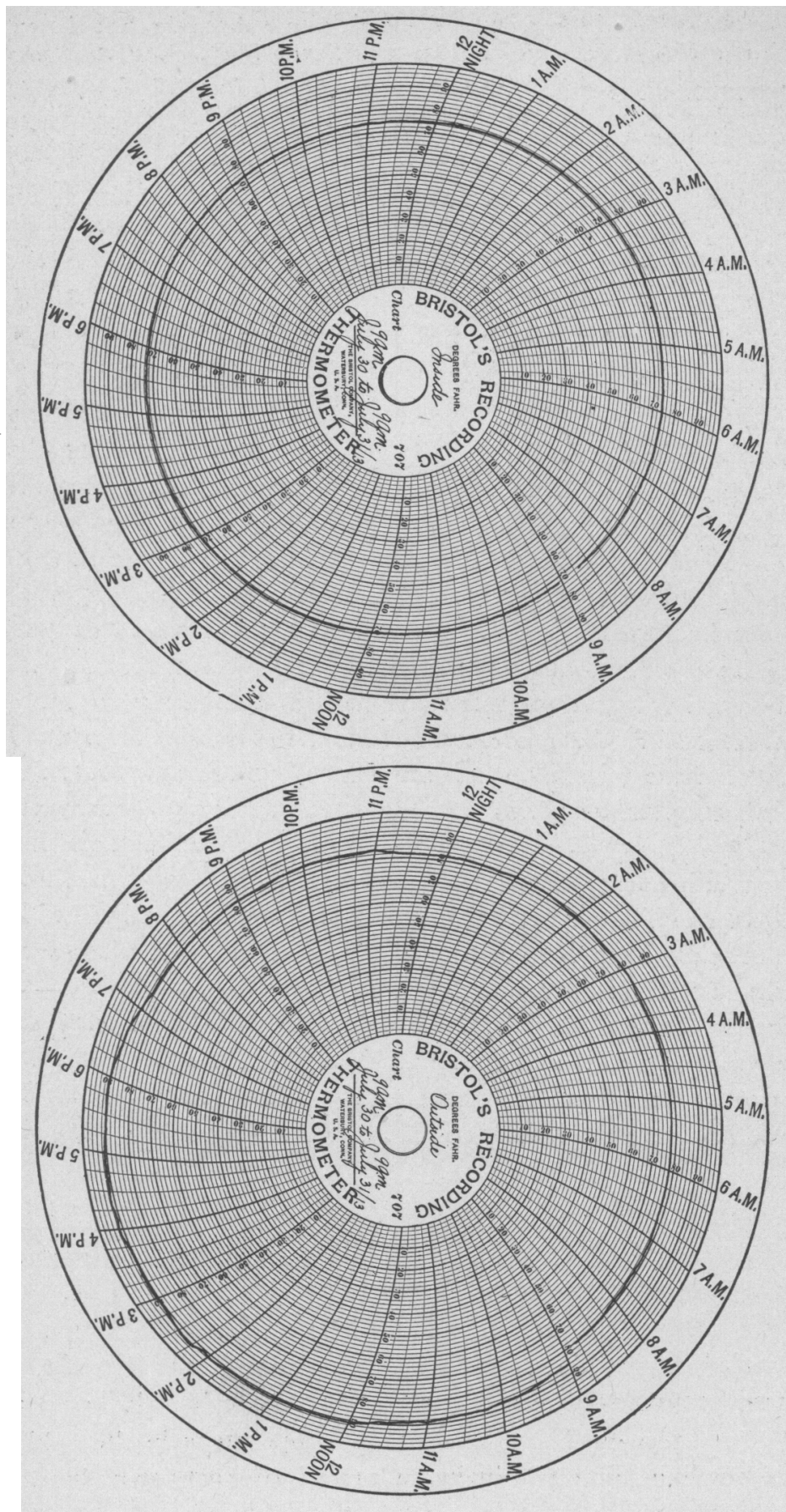

Fig. 2.-Charts showing record of inside and outside temperatures, July 30 and 31 . 


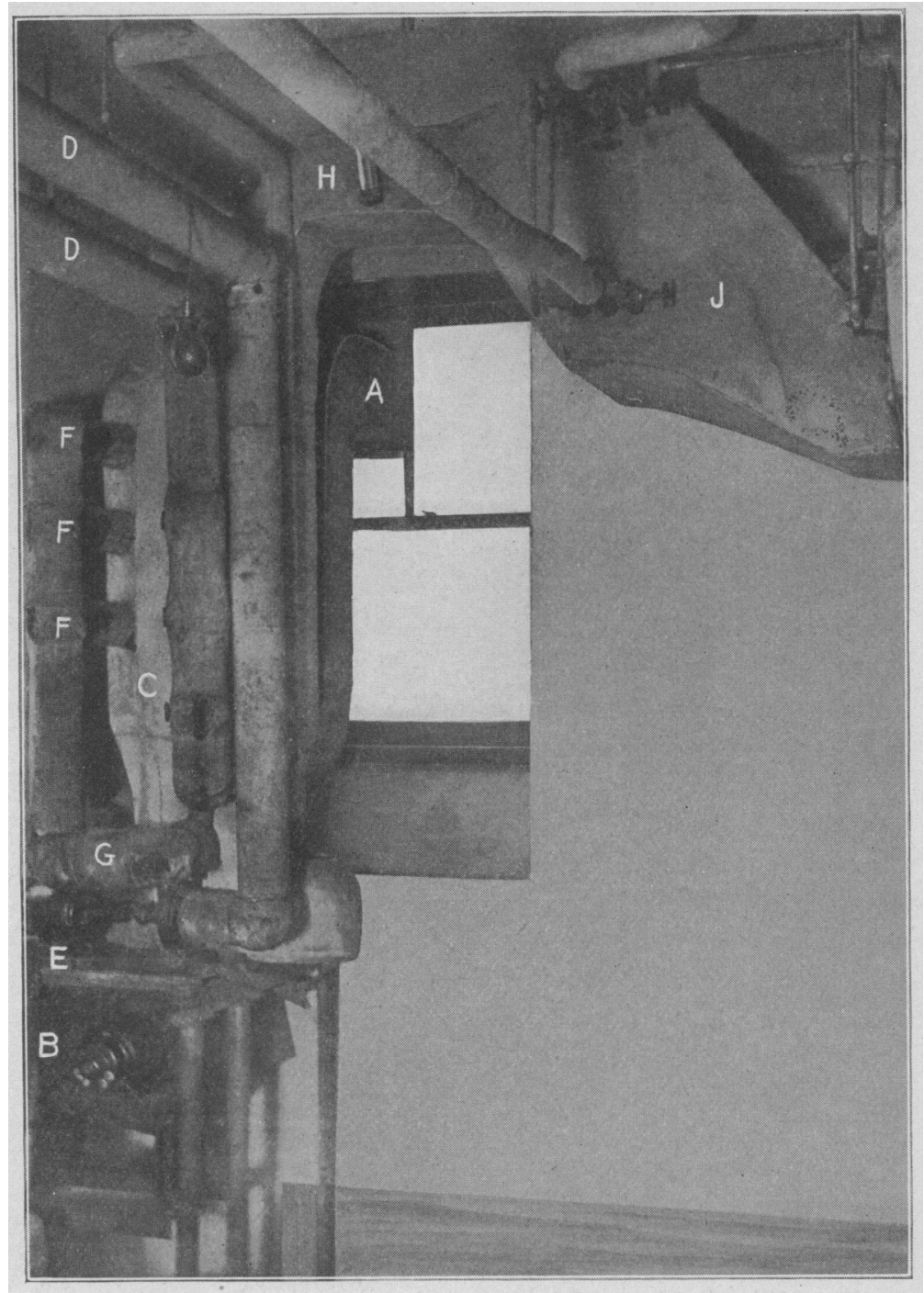

Fig. 3.- View of the air washing and cooling apparatus. The fresh air enters the duct at the point $A$ in the upper sash of the window. At $B$ may be seen the blower which delivers to the cooler-washer and cooling coils in chamber $C$. The pipes $\mathrm{D} D$, are brine pipes tapping the return brine line of the general refrigerating system of the building. At $\mathrm{E}$ is the small pump for securing a positive circulation of the brine. The brine pump delivers to the washer through the pipe $G$ and to the three coils above the washer $F, F, F$. At $H$ is the delivery duct from the air washer and $J$ is the reheating chamber, fitted, as indicated, with thermostatic control, the reheating coil also divided into three sections and the sections having hand valve control in the usual way. Incidentally the brine pipes are provided with thermometer wells and a thermometer is shown at the side of the duct to obtain readings of the air on delivery from the air-washer cooling system. A thermometer was also arranged for on the delivery side of the reheating chamber, so that arrangements are available for making a comprehensive test. 
records of the outdoor temperature during the same forty-two days, taken at 8 a. m., 12 m., 4 p. m., 8 p. m., 12 p. m. and 4 a. m., were $77,79,79,80,74$ and $70 \mathrm{~F}$., respectively. The temperature of the cold room was at all times from 5 to 11 degrees below that of the outside air.

The relative humidity was observed at different intervals during the day. In the artificially cooled room, the relative humidity varied between 41 and 76, making an average of 60 for readings taken on twenty-five different days. In the main ward, the relative humidity varied during the same period from 35 to 80 , with an average of 59 .

It is interesting to note that while low temperatures were obtained in the cold room, the relative humidity was approximately the same percentage as that in the main ward with higher temperature, thus indicating that the absolute humidity was reduced by the process of cooling.

Thirteen selected cases were treated, the average period of treatment being about two weeks. By selected cases is meant patients suffering from gastro-enteritis, ruling out premature and moribund infants. Six of the thirteen were in poor condition at the time of admission. One of these died shortly after entering the hospital. All the others were discharged from the hospital well. The treatment in all these cases was not different from that ordinarily carried out; this included Eiweissmilch, skimmed milk or barley water, plus the usual symptomatic medication.

Inasmuch as only thirteen cases of gastro-intestinal diseases were treated in the artificially cooled ward, it is hardly justifiable to present definite conclusions as to the therapeutic value of this measure. Gastro-enteritis was not particularly prevalent during the summer of 1913 , and the number of cases treated in the hospital was very much below the number usually treated; in fact, the thirteen patients who were treated in the cooled ward were practically all the gastroenteritis cases available for our first tentative studies. Thus there was no opportunity for comparison of the behavior of these cases with that of patients treated for the same disease in the open wards, under ordinary conditions. While unable at the present time to draw far-reaching conclusions, we have nevertheless gained the impression that the babies treated in this ward were, on the whole, more comfortable, cried less often, looked less sick and less parched, rested and slept better than the patients kept in the other wards of the children's service during the same time.

It is not our intention to belittle the present methods of treatment of this disease, as well as the efforts of the Board of Health, the Social Welfare Department, milk depots and other associations for 
the prevention of infant mortality, but simply to introduce this additional therapeutic measure as a valuable adjuvant in the eradication of this malady. The only cases in which this method may be harmful are in weaklings, premature and moribund infants, in whose cases extreme heat is a powerful factor in sustaining life. In all other cases of gastro-enteritis, no matter how severe, the artificial cooling of the sick-room will in our opinion prove to be an extremely helpful measure.

I hope to have the opportunity of studying this important question further this summer. I wish to thank Dr. Louis $\mathrm{H}$. Levy and Dr. A. Brody for their kind assistance in carrying out these observations.

30 West Eighty-Eighth Street. 